\title{
Minimally invasive right colectomy with transrectal natural orifice extraction: could this be the next step forward?
}

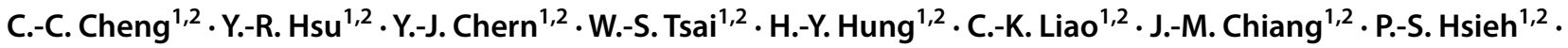 \\ J.-F. You ${ }^{1,2} \mathbb{C}$
}

Received: 12 February 2020 / Accepted: 23 June 2020 / Published online: 6 July 2020

(c) The Author(s) 2020

\begin{abstract}
Background The transvaginal natural orifice specimen extraction (NOSE) approach for right-side colon surgery has been proven to exhibit favorable short-term outcomes. However, thus far, no study has reported the advantages of transrectal NOSE for right-side colon surgery. The aim of this study was to compare the technical feasibility, safety, and short-term outcomes of minimally invasive right hemicolectomy using the transrectal NOSE method and those of conventional mini-laparotomy specimen extraction.

Methods A study was conducted on consecutive patients who had minimally invasive right hemicolectomy either for malignancy or benign disease at Chang Gung Memorial Hospital, Linkou, Taiwan, between January 2017 and December 2018. The patients were divided into two groups: conventional surgery with specimen extraction using mini-laparotomy and NOSE surgery. Surgical outcomes, including complications, postoperative short-term recovery, and pain intensity, were analyzed. Results We enrolled 297 patients (151 males, mean age $64.9 \pm 12.8$ years) who had minimally invasive right hemicolectomy. Of these 297 patients, 272 patients had conventional surgery with specimen extraction through mini-laparotomy and 25 patients had NOSE surgery (23 transrectal, 2 transvaginal). The diagnosis of colon disease did not differ significantly between the conventional and NOSE groups. Postoperative morbidity and mortality rates were comparable. The postoperative hospital stay was significantly $(p=0.004)$ shorter in the NOSE group (median 5 days, range 3-17 days) than in the conventional group (median 7 days, range $3-45$ days). Postoperative pain was significantly ( $p=0.026$ on postoperative day 1 and $p=0.002$ on postoperative day 2) greater in the conventional group than in the NOSE group.

Conclusions NOSE was associated with acceptable short-term surgical outcomes that were comparable to those of conventional surgery. NOSE results in less postoperative wound pain and a shorter hospital stay than conventional surgery. Larger studies are needed
\end{abstract}

Keywords Minimally invasive surgery $\cdot$ Right colectomy $\cdot$ Right hemicolectomy $\cdot$ Natural orifice specimen extraction (NOSE) · Laparoscopic surgery

\section{Introduction}

J.-F. You

jenodyssey@gmail.com

1 Division of Colon and Rectal Surgery, Chang Gung Memorial Hospital, Linkou, Chang Gung University College of Medicine, No. 5, Fu-Hsing St., Kuei-Shan, Taoyuan, Taiwan

2 School of Medicine, Chang Gung University, Taoyuan, Taiwan
Minimally invasive surgery for colorectal disease is a global trend. Over the past 30 years, minimally invasive colorectal surgery has been shown to cause less postoperative pain, earlier return of bowel function, shorter hospital stays, and fewer wound complications than open surgery [1, 2]. In addition to providing more favorable short-term outcomes than conventional surgery, the long-term outcomes of minimally invasive colectomy and those of open surgery are comparable [2-6]. However, in colorectal surgery, the specimen is extracted through a mini-laparotomy, which entails a 3-8$\mathrm{cm}$ incision depending on the size of specimen. Abdominal 
incision wounds may negate many of the benefits of minimally invasive surgery [7]. Thanks to the advances made in minimally invasive colorectal surgery, natural orifice specimen extraction (NOSE) surgery can prevent the minilaparotomy wound.

NOSE surgery was first published in early 1990s. In 1991 and 1992, reports by Stewart et al. [8] and Nezhat [9], respectively, described the extraction of a colectomy specimen through the vagina. Franklin et al. first described colectomy with specimen extraction through the anus in 1993 [10]. Left-side colectomy by the transrectal NOSE method is safe and feasible in some patients; the short-term outcomes include less postoperative pain and a shorter hospital stay than the conventional method. Furthermore, the long-term oncological outcomes are comparable to those of conventional mini-laparotomy specimen extraction [11-13]. Extracting a specimen of the right-sided colon from the resection wound of the colon using a colonoscope is challenging because of the anatomically narrow and tortuous shape of the sigmoid colon. Eshuis' case series reported specimen extraction through colotomy; however, the extraction failed in two of ten patients because of the bulk of the specimen [14]. Karagul reported that only approximately two-thirds of the unselected laparoscopic colectomy patients were suitable for NOSE. The success rate of the NOSE method was lower in male than in female patients, and also lower for large than for small tumors [15]. Because of technical difficulty, use of NOSE is limited. Transvaginal NOSE has remained the most commonly used path to extract specimens of the right colon [16-18]. However, transvaginal NOSE is limited to female patients and sexual dysfunction after vaginal incision may cause concern. There is currently no scientific literature on the use of transrectal NOSE for extracting specimens of the right colon.

In this study, the short-term outcomes in patients who had undergone minimally invasive right hemicolectomy by the transrectal NOSE approach and those in patients who underwent the surgery by the conventional mini-laparotomy specimen extraction were compared.

\section{Materials and methods}

\section{Study design and patient selection}

Detailed information regarding clinicopathological variables was retrieved from the Colorectal Section Tumor Registry, a prospectively collected database of colorectal cancer patients in a single medical institute of Chang Gung Memorial Hospital, Taiwan, since 1995. The institutional review board approved this study (IRB no. 201901457B0).
Between January 2017 and December 2018, a total of 303 patients had undergone minimally invasive right hemicolectomy either for malignancy or benign disease. Six patients were excluded because of failed minimally invasive surgery and conversion to laparotomy. The remaining 297 patients, among whom 272 received conventional surgery with specimen extraction through mini-laparotomy and 25 received NOSE surgery, were enrolled in this study. The adoption of NOSE surgery was based on each physician's preference. However, patient characteristics, including body mass index (BMI) $>35 \mathrm{~kg} / \mathrm{m}^{2}$, the American Society of Anesthesiologists (ASA) class $>$ III, and tumor diameter of $>4 \mathrm{~cm}$, and T4 substage on clinical computed tomography (CT)scan for malignancies were not selected for NOSE surgery. There was a total of 15 surgeons included in this study, and 4 surgeons performed the NOSE procedures.

\section{Operative procedures}

Minimally invasive right hemicolectomy was performed either by a laparoscopic or robotic approach. The standard technique of performing laparoscopic right hemicolectomy involved the use of four ports. For robotic surgery, the DaVinci Xi system (Intuitive, Sunnyvale, USA) was adopted with four robotic arms. Both laparoscopic and robotic surgery involved a similar medial-to-lateral surgical strategy. In the beginning, the dissection plane was along the ileocolic vessels. The ileocolic vessels were clearly defined and divided at their roots for malignant cases. Then retroperitoneal dissection principally adhered to the methods from medial-to-lateral and bottom-to-up approaches. The plane of dissection was anterior to and upwards along the descending portion of the duodenum, lateral to the ascending colon by separating Toldt's fascia, and heading in a right superior direction along the plane above Gerota's fascia as far as possible to the hepatic flexure of the colon. Subsequently, mobilization of the lateral attachment of the bowel, including separation of the omentum, gastrocolic and hepatocolic ligaments, and lateral peritoneal attachment of the ascending colon and lower attachment of the terminal ileum, was performed to prevent tension of the anastomosis.

After complete division of the mesentery including the marginal artery, the ileocolic anastomosis was performed either by extracorporeal anastomosis (EA) or intracorporeal anastomosis (IA). For EA, the right-sided colon and terminal ileum were exteriorized through a midline incision by extending the umbilical port wound. The ileocolic anastomosis was created either by the side-to-side stapler method or end-to-end hand-sew method. For IA, the ends of the transverse colon and terminal ileum were divided using GIA staplers, and the anastomosis was created either by side-toside stapler anastomosis and the use of sutures to close the resulting opening or by the end-to-side hand-sewn method. 
For the conventional group with specimen extraction through a mini-laparotomy wound, the removal of a specimen was from the midline for EA, by extending the right lower quadrant port wound, or through a Pfannenstiel incision for IA. For the NOSE group $(n=25)$, the extraction of the specimen was either using the transvaginal $(n=2)$ or transrectal $(n=23)$ approach. The surgical steps of NOSE using the transrectal approach are shown in Fig. 1. The rectosigmoid colon lumen was blocked using a bowel clamp. After adequate rectal irrigation with povidone iodine water, the transanal endoscopic microsurgery (TEM) scope (Richard Wolf, Tubingen, Germany) was inserted through the anus and then gently pushed till it reached the upper rectum. An enterotomy was made at the upper rectum, using a suction device to clean any fecal spillage. The TEM scope was forwarded beyond the rectal opening, and then the specimen was pulled out through the TEM scope. The rectal opening was closed by barbed suture, and the air leak test was performed to identify mechanical failure. Two patients underwent right colectomy with transvaginal specimen extraction. The vagina was cleaned with povidone-iodine. The posterior vagina was opened and a double-ringed wound protector (Alexis wound retractor; Applied Medical, Rancho Santa Margarita, CA, USA) was used to protect and shorten the vaginal canal. Then the specimen was pulled out through the vaginal canal. The colpotomy incision was closed with 2-0 absorbable suture.

\section{Outcomes and covariables}

Measurement outcomes included short-term postoperative complications, recovery, and readmission. Postoperative complications were defined as morbidity occurring within 30 days and included wound-related complications (wound infection or wound dehiscence); pulmonary (atelectasis or pneumonia), cardiovascular (myocardial infarction, stroke,
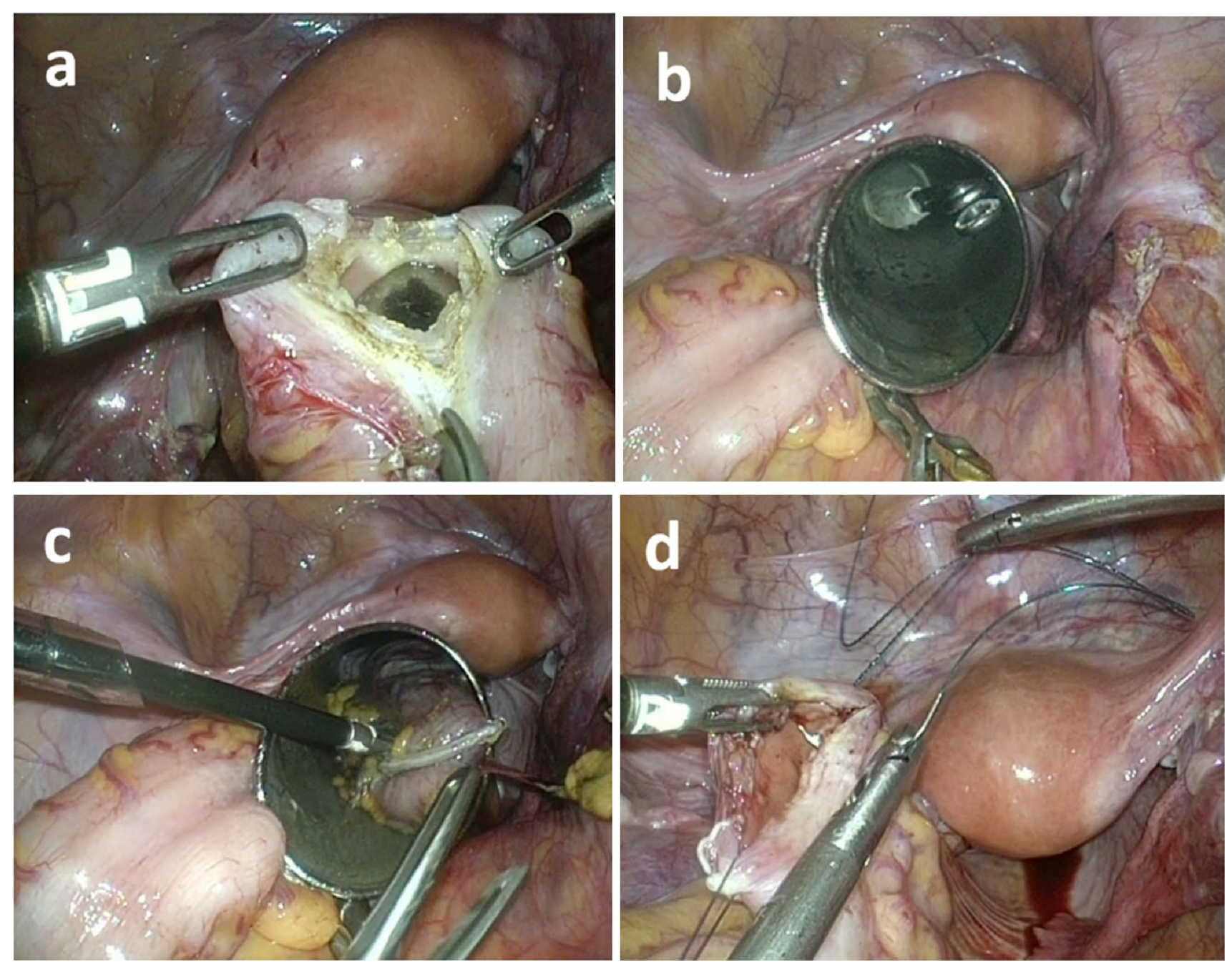

Fig. 1 Surgical steps of transrectal NOSE approach. a Enterotomy made at the upper rectum. b Transanal endoscopic microsurgery (TEM) scope forwarded beyond the rectal opening, $\mathbf{c}$ Specimen pulled out through the TEM scope. $\mathbf{d}$ Rectal opening closed by barbed suture 
or embolism), urinary (urinary tract infection or neurogenic bladder), gastrointestinal (obstruction, ileus, or bleeding), or abdominal (abscess or internal bleeding) complications; anastomosis (leakage or stenosis); and other rare complications. Postoperative mortality was defined as death occurring within 30 days after an operation. Postoperative recovery evaluation was based on blood test reports, time to first flatus and stool passage, time to diet, pain intensity, length of hospital stay. Postoperative 30-day hospital readmission data were also collected. For postoperative pain assessment, the patients were subdivided into two groups: the patientcontrolled analgesia (PCA) group and the non-PCA group. Pain intensity was assessed using a Numeric Rating Scale (NRS) with scores from 0 to $10,(10=$ the worst pain). The highest pain scores of patients on each day for 3 consecutive days postoperatively were used for further evaluation.

\section{Statistical analysis}

All analyses were conducted using IBM SPSS Statistics, Version 21.0 (Armonk, NY, USA: IBM Corp.). Clinicopathological characteristics with categorical variables were presented as frequencies and proportions and were compared using the Chi-square test. Continuous variables were expressed as means and standard deviations and were analyzed using the Student's $t$ test. Statistical significance was set at $p<0.05$.

\section{Results}

We enrolled 297 patients (151 males, mean age $64.9 \pm 12.8$ years) who underwent minimally invasive right hemicolectomy. In these 297 patients, 272 patients had conventional surgery with specimen extraction through mini-laparotomy and 25 patients had NOSE surgery (23 transrectal, 2 transvaginal). The demographic data of these patients are presented in Table 1. The two groups did not differ significantly in terms of age, sex, BMI, presence of medical illness (including hypertension, cardiac disease, cardiovascular accident, asthma, diabetes mellitus, peptic ulcer, hepatitis, liver cirrhosis, gallstone disease, and thyroid problems), and preoperative laboratory data (hemoglobin levels, white blood cell [WBC] counts, percentages of segmented WBC, serum albumin levels, blood urea nitrogen levels, creatinine levels, aspartate aminotransferase levels, and total bilirubin levels). The NOSE group had a higher rate of robotic surgery $(12.0 \%$ vs. $3.3 \%, p=0.035)$ and a higher rate of intracorporeal anastomosis $(100.0 \%$ vs. $52.6 \%, p<0.001)$ than the conventional group. The diagnosis of malignant colon disease did not differ significantly between the two groups (malignancy rate in conventional vs. NOSE, $89.3 \%$ vs. $88.0 \%, p=0.836$ ). Among the patients with malignancy (conventional vs. NOSE, 243 vs. 22), the tumors were significantly larger in the conventional than in the NOSE group (conventional vs. NOSE, $4.4 \pm 2.2 \mathrm{~cm}$ vs. $3.4 \pm 1.6 \mathrm{~cm}, p=0.007)$.

The postoperative short-term outcomes are listed in Table 2. The operating time did not differ significantly between the two groups (conventional vs. NOSE, $248.0 \pm 78.3 \mathrm{~min}$ vs. $247.8 \pm 84.4 \mathrm{~min}, p=0.988$ ). Furthermore, the blood loss during surgery did not differ significantly between the two groups. The rates of surgery combined with resection of other involved organs were similar in these two groups (conventional vs. NOSE, $9.6 \%$ vs. $8.0 \%$, $p=0.799$ ). The overall postoperative morbidity rate did not differ significantly between the two groups although the conventional group had a higher morbidity rate than the NOSE group (conventional vs. NOSE, $12.9 \%$ vs. $4.0 \%, p=0.194$ ). In the subgroup of postoperative complications, the two groups did not differ significantly in any of the postoperative variables (wound, pulmonary, cardiovascular, urinary, gastrointestinal, abdominal, and anastomosis). There was no deep or organ space surgical site infection in the NOSE group. None of the patients complained about anal bleeding, anal pain, and fecal or gas incontinence after the NOSE procedure. The reoperation rate and readmission rate did not differ significantly between the two groups. Postoperative mortality rates were comparable $(p=0.761)$ in the conventional group (1 patient, $0.4 \%)$ and NOSE group (0 patient). The mean follow-up time of the NOSE group was 13.36 months (range 1-25) months. None of the patients in the NOSE group had rectal tumor seeding during the followup period.

Postoperative clinical information is presented in Table 3. Laboratory data checked on postoperative day (POD) $3 \mathrm{did}$ not exhibit significant differences in WBC counts, percentages of segmented $\mathrm{WBC}$, and C-reactive protein (CRP) levels between the two groups. The time of first flatus was comparable in the two groups (POD $1.8 \pm 0.7$ vs. POD $2.4 \pm 1.4, p=0.066)$. The NOSE group had earlier bowel movements (POD $3.0 \pm 1.2$ vs. POD $4.2 \pm 2.0, p<0.001$ ), tolerance to liquid diet (POD $2.6 \pm 1.1$ vs. POD $4.3 \pm 2.9$, $p=0.004$ ) and tolerance to soft diet (POD $4.5 \pm 2.5 \mathrm{vs.} \mathrm{POD}$ $6.1 \pm 3.3, p=0.020)$ than the conventional group. The postoperative hospital stay was significantly shorter in the NOSE group (mean $5.2 \pm 2.8$ days, median 5 days, range 3-17 days) than in the conventional group (mean $8.3 \pm 5.1$ days, median 7 days, range $3-45$ days) $(p=0.004)$.

Figure 2 shows the difference in scores on the NRS on 3 consecutive days after operation in the two groups. The NRS scores of patients without PCA (conventional 263, NOSE 24) are shown in Fig. 2a and the scores of the patients with PCA (conventional 9, NOSE 1) are shown in Fig. 2b. The conventional group exhibited significantly higher NRS scores on POD1 and POD2 than the NOSE group (POD1, 
Table 1 Clinicopathological features of patients who underwent minimally invasive right hemicolectomy

\begin{tabular}{|c|c|c|c|c|}
\hline & Conventional (272) & NOSE (25) & Missing data & $p$ \\
\hline Age (years) & $65.3 \pm 12.7$ & $61.0 \pm 13.4$ & & 0.105 \\
\hline Sex & & & & 0.766 \\
\hline Male & $139(51.1)$ & $12(48)$ & & \\
\hline Female & $133(48.9)$ & $13(52)$ & & \\
\hline $\mathrm{BMI}\left(\mathrm{kg} / \mathrm{m}^{2}\right)$ & & & 1 & 0.375 \\
\hline $\mathrm{BMI} \leqq 25$ & $116(42.8)$ & $13(52)$ & & \\
\hline $\mathrm{BMI}>25$ & $155(57.2)$ & $12(48)$ & & \\
\hline BMI, mean & $24.7 \pm 4.2$ & $25.2 \pm 3.5$ & & 0.573 \\
\hline \multicolumn{5}{|l|}{ Medical illness } \\
\hline Hypertension & $124(45.6)$ & $9(36)$ & & 0.356 \\
\hline Cardiac disease & $25(9.2)$ & $1(4)$ & & 0.379 \\
\hline CVA & $7(2.6)$ & $1(4)$ & & 0.673 \\
\hline Asthma & $6(2.2)$ & 0 & & 0.453 \\
\hline Diabetes & $68(25)$ & $4(16)$ & & 0.315 \\
\hline Peptic ulcer & $24(8.8)$ & $1(4)$ & & 0.406 \\
\hline Hepatitis & $15(5.5)$ & $1(4)$ & & 0.748 \\
\hline Liver cirrhosis & $3(1.1)$ & 0 & & 0.598 \\
\hline Cholelithiasis & $5(1.8)$ & 0 & & 0.494 \\
\hline Thyroid problem & $9(3.3)$ & $1(4)$ & & 0.855 \\
\hline Other & $63(23.2)$ & $5(20)$ & & 0.719 \\
\hline \multicolumn{5}{|l|}{ Lab data } \\
\hline $\mathrm{Hb}(\mathrm{g} / \mathrm{dL})$ & $11.6 \pm 2.6$ & $12.4 \pm 2.4$ & & 0.153 \\
\hline WBC (/uL) & $7222 \pm 2307$ & $6532 \pm 2008$ & & 0.149 \\
\hline Seg $(\%)$ & $63.9 \pm 9.8$ & $61.5 \pm 9.7$ & 3 & 0.250 \\
\hline Albumin (g/dL) & $4.1 \pm 0.4$ & $4.2 \pm 0.4$ & 1 & 0.555 \\
\hline BUN (mg/dL) & $17.2 \pm 9.4$ & $15.8 \pm 8.0$ & 1 & 0.499 \\
\hline $\mathrm{Cr}(\mathrm{mg} / \mathrm{dL})$ & $1.0 \pm 1.1$ & $0.9 \pm 0.4$ & 2 & 0.474 \\
\hline AST (U/L) & $25 \pm 11$ & $32 \pm 34$ & 4 & 0.309 \\
\hline Total bilirubin (mg/dL) & $0.5 \pm 0.4$ & $0.6 \pm 0.3$ & & 0.113 \\
\hline Technique & & & & 0.035 \\
\hline Laparoscopic & $263(96.7)$ & $22(88)$ & & \\
\hline Robotic & $9(3.3)$ & $3(12)$ & & \\
\hline IA & $143(52.6)$ & $25(100)$ & & $<0.001$ \\
\hline Diagnosis & & & & 0.836 \\
\hline Malignant & $243(89.3)$ & $22(88)$ & & \\
\hline Benign & $29(10.7)$ & $3(12)$ & & \\
\hline Malignancy & $(n=243)$ & $(n=22)$ & & \\
\hline Tumor size $(\mathrm{cm})$ & $4.4 \pm 2.2$ & $3.4 \pm 1.6$ & 1 & 0.007 \\
\hline CEA (ng/mL) & & & & 0.381 \\
\hline $\mathrm{CEA}<5$ & $178(73.3)$ & $18(81.8)$ & & \\
\hline $\mathrm{CEA}>5$ & $65(26.7)$ & $4(18.2)$ & & \\
\hline
\end{tabular}

Values are presented as mean \pm standard deviation or number $(\%)$

NOSE natural orifice specimen extraction, $B M I$ body mass index, $C V A$ cerebrovascular accident; $H b$ hemoglobin, $W B C$ white blood cells, Seg segmented neutrophils, $B U N$ blood urea nitrogen, $C r$ creatinine, $A S T$ aspartate aminotransferase, $I A$ intracorporeal anastomosis, $C E A$ carcinoembryonic antigen conventional vs. NOSE: $4.5 \pm 1.8$ vs. $3.6 \pm 2.0, p=0.026$; POD2, conventional vs. NOSE: $3.3 \pm 1.5$ vs. $2.6 \pm 1.0$, $\mathrm{p}=0.002$ ) (Fig. 2a). The NRS did not differ in POD1-3 between the two groups (Fig. 2b).

\section{Discussion}

Minimally invasive surgery for colorectal disease has been widely accepted; this surgery causes smaller abdominal 
Table 2 Perioperative outcomes

\begin{tabular}{llll}
\hline & Conventional (272) & NOSE (25) & $p$ \\
\hline Operation time (minutes) & $248.0 \pm 78.3$ & $247.8 \pm 84.4$ & 0.988 \\
Blood loss (mL) & $45 \pm 49$ & $32 \pm 15$ & 0.185 \\
Combined surgery & $26(9.6)$ & $2(8)$ & 0.799 \\
Postoperative morbidity & $35(12.9)$ & $1(4)$ & 0.194 \\
Wound & $5(1.8)$ & 0 & 0.494 \\
Pulmonary & $1(0.4)$ & 0 & 0.761 \\
Cardiovascular & $1(0.4)$ & 0 & 0.761 \\
Urinary & $1(0.4)$ & 0 & 0.761 \\
Gastrointestinal & $14(5.1)$ & $1(4)$ & 0.802 \\
Abdominal & $7(2.6)$ & 0 & 0.417 \\
Anastomosis & $6(2.2)$ & 0 & 0.453 \\
Mortality & $1(0.4)$ & 0 & 0.761 \\
Second operation & $6(2.2)$ & 0 & 0.453 \\
Re-admission & $6(2.2)$ & 0 & 0.453 \\
\hline
\end{tabular}

Values are presented as mean \pm standard deviation or number (\%)

NOSE natural orifice specimen extraction, DVT deep vein thrombosis

wounds than open surgery. However, a mini-laparotomy wound is necessary to remove specimen. To reduce woundrelated complications and achieve superior cosmetic results, the NOSE procedure was developed. The advantages and disadvantages of conventional and NOSE surgery for right colectomy are summarized in Table 4 . Some studies have reported that laparoscopic right hemicolectomy with transvaginal specimen retrieval is feasible with favorable shortterm surgical outcomes [16-18]. Transanal extraction of the sigmoid colon and rectum specimens also has acceptable short-term and long-term outcomes [11, 13]. In this study, we mainly performed minimally invasive right hemicolectomy using the NOSE method to extract the specimen transrectally. The transvaginal method can also be used in the NOSE procedure; however, colpotomy incision repair is more difficult than rectal repair. An incision was made longitudinally over the upper rectum, and suture repair was quite simple. In addition, transrectal specimen removal can be performed in male and female patients and can avoid adverse effects on sexual function. Some researchers have expressed concern about the bacteriological safety of the transrectal method because the rectum is opened for specimen retrieval. We observed that no significant postoperative morbidity and changes in laboratory data are observed if the rectum is cleaned properly. To our knowledge, our study is the first evaluating short-term surgical outcomes of minimally invasive right hemicolectomy performed using transrectal NOSE.

Avoidance of the mini-laparotomy wound for specimen extraction is one of the most crucial features of NOSE. Compared with conventional minimally invasive surgery, NOSE causes less postoperative pain, results in faster recovery, and provides superior cosmetic results. A previous study demonstrated favorable short-term surgical outcomes after performing laparoscopic right hemicolectomy using the transvaginal NOSE [18]. Patients who had undergone NOSE experienced less pain and required shorter hospital stays than those who had undergone conventional surgery, without significant differences in surgical morbidity. Two randomized clinical trials that compared the short-term operative outcomes in patients with left-sided colonic disease [19,20]. They demonstrated that NOSE group experienced less wound pain and had a lower wound infection rate than the conventional group. In our study, no significant differences were observed in the operation time, blood loss, and postoperative morbidity between the two groups. The postoperative pain scores did not differ significantly in the two groups among patients with PCA. As regards patients without PCA, the NOSE group experienced less wound pain than the conventional group. The benefit of NOSE was observed on POD 1 and
Table 3 Postoperative laboratory data and recovery parameters

\begin{tabular}{lllr}
\hline & Conventional (272) & NOSE $(25)$ & $p$ \\
\hline POD3 lab data & & & \\
WBC (/uL) & $9606 \pm 2959(n=245)$ & $10,264 \pm 2327(n=22)$ & 0.312 \\
Seg (\%) & $77.3 \pm 7.2(n=245)$ & $79.4 \pm 7.5(n=22)$ & 0.177 \\
CRP (mg/L) & $82.5 \pm 52.2(n=245)$ & $72.4 \pm 36.6(n=22)$ & 0.379 \\
First flatus passage (days) & $2.4 \pm 1.4$ & $1.8 \pm 0.7$ & 0.066 \\
First stool passage (days) & $4.2 \pm 2.0$ & $3.0 \pm 1.2$ & $<0.001$ \\
Tolerate liquid diet (days) & $4.3 \pm 2.9$ & $2.6 \pm 1.1$ & 0.004 \\
Tolerate soft diet (days) & $6.1 \pm 3.3$ & $4.5 \pm 2.5$ & 0.020 \\
Mean postoperative hospital stay (days) & $8.3 \pm 5.1$ & $5.2 \pm 2.8$ & 0.004 \\
Median postoperative hospital stay (days) & $7(3-45)$ & $5(3-17)$ & \\
\hline
\end{tabular}

Values are presented as mean \pm standard deviation unless otherwise indicated

NOSE natural orifice specimen extraction, $P O D$ postoperative day, $W B C$ white blood cells, Seg segmented neutrophils, $C R P$ C-reactive protein 
(a)

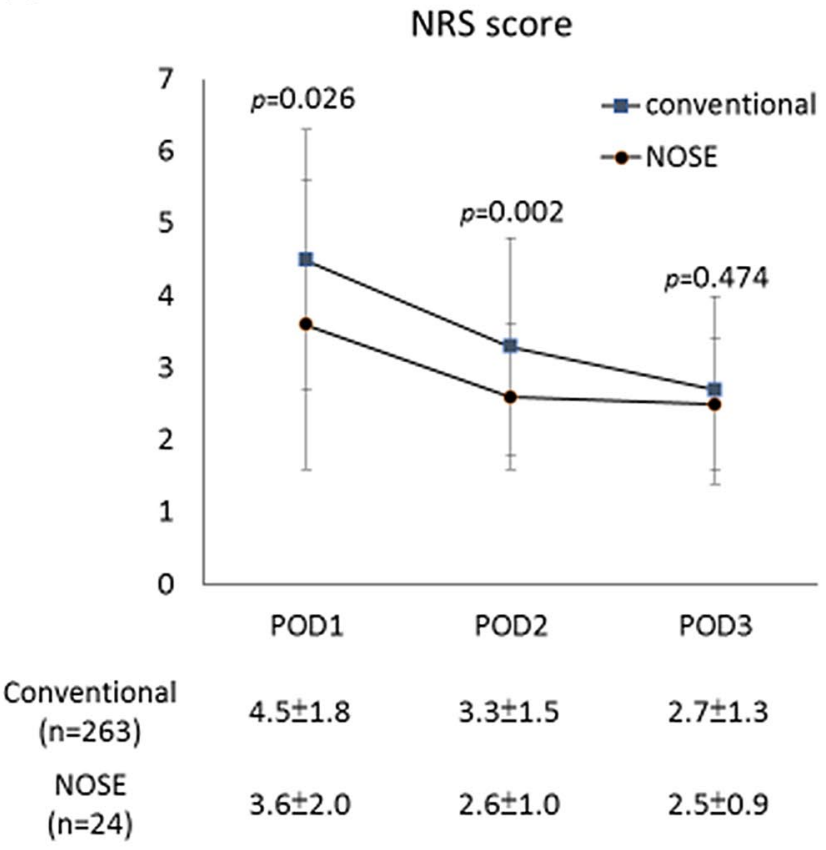

(b)

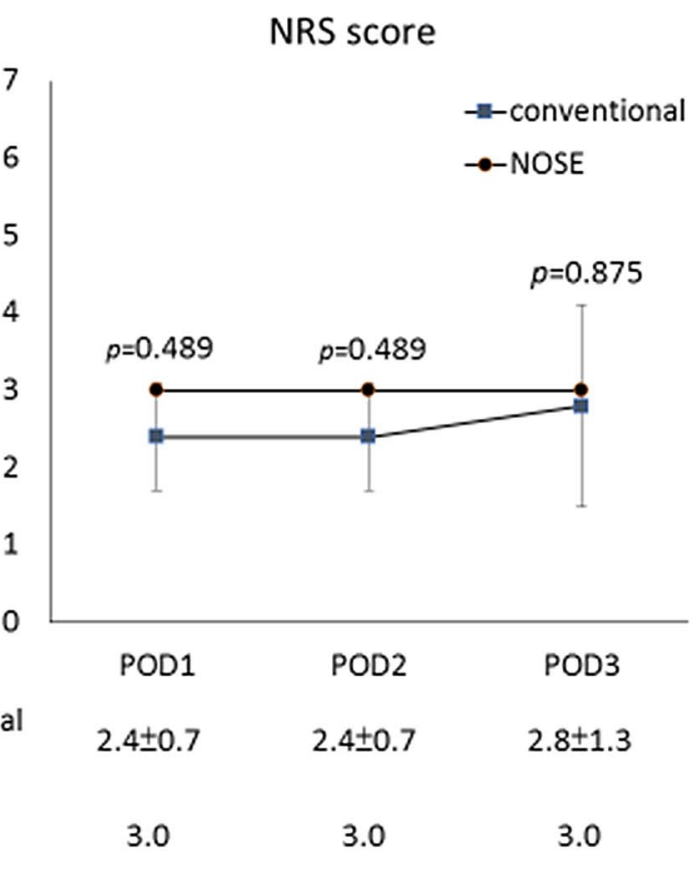

Fig. 2 Postoperative pain scores in patients without patient-controlled analgesia (a) and patients with patient-controlled analgesia (b). Values are presented as mean \pm standard deviation. NRS Numeric Rating Scale, NOSE natural orifice specimen extraction, POD postoperative day

Table 4 Summary and comparison of conventional and NOSE surgery for right colectomy

\begin{tabular}{lll}
\hline Variable & Conventional & NOSE \\
\hline Wound size & Larger & Smaller \\
Wound pain & More & Less \\
Anastomosis leakage & Equal & Equal \\
Intraabdominal abscess & Equal & Equal \\
Rectal complication & No & Potential \\
Bowel recovery & Slower & Faster \\
Hospital stay & Longer & Shorter \\
Specimen size restriction & No & Yes \\
Intracorporeal suture technique & Optional & Required \\
Wound-related complications & More & Less \\
\hline
\end{tabular}

NOSE natural orifice specimen extraction

POD2. Previous studies have reported time to flatus passage of approximately $2.7-3$ days and time to resumption of a regular diet of approximately 4-4.6 days for patients who had undergone transvaginal NOSE $[17,18]$. Faster bowel recovery and earlier food intake were observed in the NOSE group than in the conventional group. Early ambulation and less use of analgesic agents because of less postoperative pain may be the reasons. This can help to shorten the hospital stay. Surgical site infection occurs after conventional laparoscopic right hemicolectomy in
$5-7 \%$ of cases $[21,22]$. None of our patients who had NOSE experienced wound-related complications.

Bacterial contamination is always a concern during the NOSE procedure. We strongly suggest that mechanical bowel preparation, intraoperative transanal lavage with povidone iodine solution, transluminal wound protector, and prophylactic antibiotics are applied to reduce the bacterial load [23]. Recently, a study showed that the risk of bacterial contamination with NOSE was not significantly higher than that in conventional laparoscopic surgery [24]. In our study, patients who had NOSE did not experience significant postoperative morbidity or laboratory data changes, such as leukocytosis, or CRP level elevation, than the conventional group. None of our patients have had rectal wound-related complications or leakage thus far.

Tumor size is considered before applying the NOSE procedure. Many authors limit indications to tumors smaller than $3[25,26], 4[27,28], 5[29,30], 6[31]$, or 6.5 [32] cm. The average tumor size in the NOSE group in our study was $3.4 \mathrm{~cm}$, and it was significantly smaller than that in the conventional group. Some authors have stated that obese patients are not suitable for transrectal specimen extraction and set the BMI cutoff at $>28 \mathrm{~kg} / \mathrm{m}^{2}$ [32], $>30 \mathrm{~kg} / \mathrm{m}^{2}$ [29], or $>35 \mathrm{~kg} /$ $\mathrm{m}^{2}$ [33]. In our study, although no significant difference in patients' BMI was seen in the two groups, the highest BMI was $32 \mathrm{~kg} / \mathrm{m}^{2}$ in the NOSE group and $40 \mathrm{~kg} / \mathrm{m}^{2}$ in the conventional group. Patients with a bulky mesocolon, a narrow pelvis, and 
previous pelvic surgery with severe adhesions were not eligible for NOSE.

This study has some limitations. First, the retrospective analysis of prospectively collected data might have caused some selection bias. Notably, the NOSE group is a highly selective patient group, which is not comparable to the conventional group. Second, the sample size is relatively small in the NOSE group, which might have resulted in a lack of statistical power. Third, this study only reports on short-term outcomes and lacks long-term oncologic outcome follow-up; however, the use of the NOSE procedure in the left colon is well established.

\section{Conclusions}

Transrectal NOSE can be performed in some patients who require minimally invasive right hemicolectomy with postoperative short-term outcomes that are comparable to those of conventional laparoscopic surgery. NOSE is associated with less postoperative wound pain, faster bowel recovery, and shorter hospital stay than the conventional method. Additional prospective studies with larger patient populations and longer follow-up are warranted.

Acknowledgements This manuscript was edited by Wallace Academic Editing. We thank Reiping Tang, MD., Jinn-Shium Chen,MD., SumFu Chiang, MD., Chien-Yuh Yeh, MD., Yueh-Chen Lin. MD., and Cheng-Chou Lai, MD, for assistance with the acquisition of data and comments that greatly improved the manuscript.

Author contributions $\mathrm{CCC}$ and YJF made substantial contribution to the study conception and design. HYJ and CYJ assisted in analysis and interpretation of data. CCC, YJF, HYJ and CYJ participated in drafting the article. TWS, HHY, LCK, HPS and CJM contributed to the acquisition of data and revised the manuscript critically for important intellectual content. HHY assisted in data verification. All authors read and approved the final manuscript.

Funding There are no financial conflicts of interest to disclose.

\section{Compliance with ethical standards}

Conflict of interest The authors declare that they have no conflicts of interest.

Ethical approval All procedures performed in studies involving human participants were in accordance with the ethical standards of the institutional review board.

Informed consent Informed consent was obtained from all individual participants involved in the study.

Open Access This article is licensed under a Creative Commons Attribution 4.0 International License, which permits use, sharing, adaptation, distribution and reproduction in any medium or format, as long as you give appropriate credit to the original author(s) and the source, provide a link to the Creative Commons licence, and indicate if changes were made. The images or other third party material in this article are included in the article's Creative Commons licence, unless indicated otherwise in a credit line to the material. If material is not included in the article's Creative Commons licence and your intended use is not permitted by statutory regulation or exceeds the permitted use, you will need to obtain permission directly from the copyright holder. To view a copy of this licence, visit http://creativecommons.org/licenses/by/4.0/.

\section{References}

1. Color Study Group (2000) COLOR: a randomized clinical trial comparing laparoscopic and open resection for colon cancer. Dig Surg 17(6):617-622

2. Clinical Outcomes of Surgical Therapy Study Group (2004) A comparison of laparoscopically assisted and open colectomy for colon cancer. N Engl J Med 350(20):2050-2059

3. Fleshman J, Sargent DJ, Green E, Anvari M, Stryker SJ, Beart RW Jr, Hellinger M, Flanagan R Jr, Peters W, Nelson H (2007) Laparoscopic colectomy for cancer is not inferior to open surgery based on 5-year data from the COST Study Group trial. Ann Surg 246(4):655-662 (discussion 662-654)

4. Lacy AM, Delgado S, Castells A, Prins HA, Arroyo V, Ibarzabal A, Pique JM (2008) The long-term results of a randomized clinical trial of laparoscopy-assisted versus open surgery for colon cancer. Ann Surg 248:1-7

5. Green BL, Marshall HC, Collinson F, Quirke P, Guillou P, Jayne DG, Brown JM (2013) Long-term follow-up of the Medical Research Council CLASICC trial of conventional versus laparoscopically assisted resection in colorectal cancer. Br J Surg 100(1):75-82

6. Deijen CL, Vasmel JE, de Lange-de Klerk ESM et al (2017) Tenyear outcomes of a randomised trial of laparoscopic versus open surgery for colon cancer. Surg Endosc 31(6):2607-2615

7. Laurent C, Leblanc F, Bretagnol F, Capdepont M, Rullier E (2008) Long-term wound advantages of the laparoscopic approach in rectal cancer. Br J Surg 95(7):903-908

8. Stewart EA, Liau AS, Friedman AJ (1991) Operative laparoscopy followed by colpotomy for resecting a colonic leiomyosarcoma: a case report. J Reprod Med 36(12):883-884

9. Nezhat F, Nezhat C, Pennington E, Ambroze W Jr (1992) Laparoscopic segmental resection for infiltrating endometriosis of the rectosigmoid colon: a preliminary report. Surg Laparosc Endosc 2(3):212-216

10. Franklin ME Jr, Ramos R, Rosenthal D, Schuessler W (1993) Laparoscopic colonic procedures. World J Surg 17(1):51-56

11. Park JS, Kang H, Park SY, Kim HJ, Lee IT, Choi GS (2018) Long-term outcomes after Natural Orifice Specimen Extraction versus conventional laparoscopy-assisted surgery for rectal cancer: a matched case-control study. Ann Surg Treat Res 94(1):26-35

12. Zattoni D, Popeskou GS, Christoforidis D (2018) Left colon resection with transrectal specimen extraction: current status. Tech Coloproctol 22(6):411-423

13. Chen C, Chen H, Yang M, Wu X, Yuan X, Zhu C, Han Y, Yin L (2019) Laparoscopy-assisted natural orifice specimen extraction to treat tumors of the sigmoid colon and rectum: the short- and long-term outcomes of a retrospective study. J Laparoendosc Adv Surg Tech A 29(6):801-808

14. Eshuis EJ, Voermans RP, Stokkers PC, van Berge Henegouwen MI, Fockens P, Bemelman WA (2010) Laparoscopic resection with transcolonic specimen extraction for ileocaecal Crohn's disease. Br J Surg 97(4):569-574

15. Karagul S, Kayaalp C, Sumer F, Ertugrul I, Kirmizi S, Tardu A, Yagci MA (2017) Success rate of natural orifice specimen extraction after laparoscopic colorectal resections. Tech Coloproctol 21(4):295-300 
16. Franklin ME Jr, Kelley H, Kelley M, Brestan L, Portillo G, Torres J (2008) Transvaginal extraction of the specimen after total laparoscopic right hemicolectomy with intracorporeal anastomosis. Surg Laparosc Endosc Percutan Tech 18(3):294-298

17. Park JS, Choi GS, Lim KH, Jang YS, Kim HJ, Park SY, Jun SH (2010) Clinical outcome of laparoscopic right hemicolectomy with transvaginal resection, anastomosis, and retrieval of specimen. Dis Colon Rectum 53(11):1473-1479

18. Park JS, Choi GS, Kim HJ, Park SY, Jun SH (2011) Natural orifice specimen extraction versus conventional laparoscopically assisted right hemicolectomy. Br J Surg 98(5):710-715

19. Leung AL, Cheung HY, Fok BK, Chung CC, Li MK, Tang CN (2013) Prospective randomized trial of hybrid NOTES colectomy versus conventional laparoscopic colectomy for left-sided colonic tumors. World J Surg 37(11):2678-2682

20. Wolthuis AM, Fieuws S, Van Den Bosch A, de Buck van Overstraeten A, D'Hoore A (2015) Randomized clinical trial of laparoscopic colectomy with or without natural-orifice specimen extraction. Br J Surg 102(6):630-637

21. Zheng MH, Feng B, Lu AG, Li JW, Wang ML, Mao ZH, Hu YY, Dong F, Hu WG, Li DH, Zang L, Peng YF, Yu BM (2005) Laparoscopic versus open right hemicolectomy with curative intent for colon carcinoma. World J Gastroenterol 11(3):323-326

22. Tan WS, Chew MH, Ooi BS, Ng KH, Lim JF, Ho KS, Tang CL, Eu KW (2009) Laparoscopic versus open right hemicolectomy: a comparison of short-term outcomes. Int J Colorectal Dis 24(11):1333-1339

23. Leroy J, Costantino F, Cahill RA, D’Agostino J, Morales A, Mutter D, Marescaux J (2011) Laparoscopic resection with transanal specimen extraction for sigmoid diverticulitis. Br J Surg 98(9):1327-1334

24. Ngu J, Wong AS (2016) Transanal natural orifice specimen extraction in colorectal surgery: bacteriological and oncological concerns. ANZ J Surg 86(4):299-302

25. Shimizu H, Adachi K, Ohtsuka H, Osaka I, Takuma K, Takanishi K, Matsumoto J (2017) Totally laparoscopic resection for low sigmoid and rectal cancer using natural orifice specimen extraction techniques. Surg Laparosc Endosc Percutan Tech 27(4):e74-e79
26. Guan X, Liu Z, Longo A et al (2019) International consensus on natural orifice specimen extraction surgery (NOSES) for colorectal cancer. Gastroenterol Rep (Oxf) 7(1):24-31

27. Saad S, Hosogi H (2011) Laparoscopic left colectomy combined with natural orifice access: operative technique and initial results. Surg Endosc 25(8):2742-2747

28. Wolthuis AM, de Buck van Overstraeten A, Fieuws S, Boon K, D'Hoore A et al (2015) Standardized laparoscopic NOSEcolectomy is feasible with low morbidity. Surg Endosc 29(5):1167-1173

29. Hisada M, Katsumata K, Ishizaki T, Enomoto M, Matsudo T, Kasuya K, Tsuchida A (2014) Complete laparoscopic resection of the rectum using natural orifice specimen extraction. World $\mathrm{J}$ Gastroenterol 20(44):16707-16713

30. Saurabh B, Chang SC, Ke TW, Huang YC, Kato T, Wang HM, Tzu-Liang Chen W, Fingerhut A (2017) Natural orifice specimen extraction with single stapling colorectal anastomosis for laparoscopic anterior resection: feasibility, outcomes, and technical considerations. Dis Colon Rectum 60(1):43-50

31. Xingmao Z, Haitao Z, Jianwei L, Huirong H, Junjie H, Zhixiang $Z$ (2014) Totally laparoscopic resection with natural orifice specimen extraction (NOSE) has more advantages comparing with laparoscopic-assisted resection for selected patients with sigmoid colon or rectal cancer. Int J Colorectal Dis 29(9):1119-1124

32. Huang CC, Chen YC, Huang CJ, Hsieh JS (2016) Totally laparoscopic colectomy with intracorporeal side-to-end colorectal anastomosis and transrectal specimen extraction for sigmoid and rectal cancers. Ann Surg Oncol 23(4):1164-1168

33. Wolthuis AM, Meuleman C, Tomassetti C, D'Hooghe T, Fieuws S, Penninckx F, D’Hoore A (2011) Laparoscopic sigmoid resection with transrectal specimen extraction: a novel technique for the treatment of bowel endometriosis. Hum Reprod 26(6):1348-1355

Publisher's Note Springer Nature remains neutral with regard to jurisdictional claims in published maps and institutional affiliations. 